$\xi=-1$

\title{
Prediction on Hand Arm Vibration Exposure Cause-Effect among Grass-Cutting Workers in Malaysia
}

\author{
Mohamad Hanafi Ali ${ }^{1}$, Nor Azali Azmir ${ }^{2 *}$, Musli Nizam Yahya ${ }^{2}$

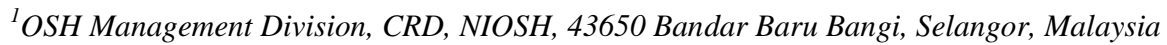 \\ ${ }^{2}$ Department of Engineering Mechanics, Faculty of Mechanical and Manufacturing Engineering, Universiti Tun Hussein Onn Malaysia, \\ 84600 Parit Raja, Johor, Malaysia \\ *Corresponding authorE-mail : azali@uthm.edu.my
}

\begin{abstract}
Prolonged exposures to hand-transmitted vibrations from grass-cutting machines have been associated with increasing occurrences of signs of occupational diseases related to the hand-arm vibration syndrome (HAVS). However, there are no specific processes available that cover the subjective and objective health cause-effects of the hand arm vibration risk factors during onsite operations. The objectives are (1) to measure the health subjective and objective risks during normal working conditions among hand-held grass-cutting workers and (2) to determine the significant correlation of the subjective and objective measurement variables of the Hand Arm Vibration Exposure Risk Assessment (HAVERA) on hand arm vibration symptoms and disorders. The study was conducted in two stages: evaluation of the HAVERA variables and development of the health prediction cause-effect model of the HAVERA process using multiple linear regressions and feed forward neural network programming. In the onsite measurement, the daily vibration value depicted an exceeded exposure action value of $2.5 \mathrm{~m} / \mathrm{s} 2$ for both hands; and experiences of any finger colour change were claimed by $80 \%$ of the 204 subjects. This shows that HAVERA process provided a good indication of HAVS which are reported as vascular, neurological and musculoskeletal disorders. In the right and left hand prediction model development, the results demonstrated a higher reliability performance as compared to the linear model for hand grip strength and hand numerical scoring assessment. The prediction of the HAVERA model using the neural network method has been developed for monitoring health conditions due to hand-transmitted vibrations among hand-held grasscutting workers in Malaysia.
\end{abstract}

Keywords: Hand Arm Vibration; Occupational Disease; Grass Cutter; Risk Assessment; Reliability

\section{Introduction}

Hand-transmitted vibration (HTV) is a common physical hazard for occupational safety and health which is caused by harmful activities to workers who use vibrating equipment in their routine tasks [1]. The fundamental HTV evaluation is often an initial process for employers to evaluate hand-transmitted assessment due to the hand arm vibration hazard at workplace among their employees $[2,3,4]$. With this evaluation, it will assist the employers to measure whether the works or activities are exposed to risk factor that could induce hand arm vibration syndrome (HAVS). By measuring the HTV exposure towards health cause-effect factors; it also assists the employers to decrease the cost of occupational rehabilitations and work-related injuries [5,6,7,8]. In European countries, there is regulatory requirement to perform HTV exposure at workplace to improve employees' health quality and this can be associated to the responsibility and accountability of employers $[3,4]$.

It is an important requirement for the risk measurement, evaluation and assessment of hand arm vibration exposure among handheld vibrating machine workers to be taken in the monitoring process of the safety and health management $[1,2,6]$. The rationale of this study was established from occupational hand arm vibration knowledge for epidemiological methods used to identify and analyze the health cause-effects induce in a work related with vascular, neurological and musculoskeletal disorders at workplace.
Hence, its principle method is to define a subjective and objective measures linked with the development of hand arm vibration syndrome (HAVS) which has a significant element for HTV in developing the health cause-effect of hand arm vibration exposure in Malaysia $[9,10,11,12,13]$. The investigation of hand arm vibration exposure to the health cause-effect associated to the HAVS is becoming a major interest for both human factor and occupational health in conducting their research study $[11,12,13]$.

Statistics of occupational accidents by sector, which caused death, permanent disability and non-permanent disability, have been widely investigated and represented a significant problem to the Malaysian industries. According to the Department of Occupational Safety and Health (DOSH) report on occupational accidents for the non-permanent disabilities category until December 2013, about 1496 cases of non-permanent disability were reported by the manufacturing industries which show the highest cases. The agriculture, forestry, logging and fishing industry was the second highest of 488 cases of non-permanent disability reported, followed by utility industry (100 cases of casualties) and the transportation, storage and communication industry (84 cases of casualties) [14]. There were 161 compensation claims under musculoskeletal disorder. The increasing number of occupational diseases showed about 110 workers applied to the Social Security Organization (SOCSO) for compensation claims under the item diseases caused by vibration (disorders of muscles, tendons, bones, joints, peripheral blood vessels or peripheral nerves) [15]. 
Hand arm vibration injuries begins with the workers exposing vibration transmitted energy to hand palm; hence experiencing discomfort or pain after operating hand-held vibrating equipment at a workplace $[10,11,16,17,18]$. Due to the magnitude, frequency and duration of HTV exposure at workplaces, the discomfort will lead to an increase of severity of symptoms and will experience hand pains and injuries $[10,11,18]$. The hand pains and injuries may eventually result in vascular, neurological and musculoskeletal disorders such as numbness, tingling, loss of finger sensation, or finger colour changes such as vibration induced white fingers $[18,19,20]$.

Recent approaches to assess the exposure of hand-transmitted vibration (HTV) associated to hand arm vibration syndrome (HAVS) were using the observation, interview and measurement methods, mainly because it was reasonably practical for application in a broad variety of hand-held vibrating machine. In contrast to the other methods especially in determining the health causeeffect would be difficult because of the medical complication and cost increase [2,10,18,21].

Although there is established standard operating procedure to monitor the diagnosis of HTV exposure health cause-effect at workplace such as vibration magnitude and duration [22], observation [23], questionnaires interview [21] and vibrotactile perception threshold [11], a need to improve the risk control measure either by engineering or administrative of HTV exposure and to investigate the interactions between variables especially in Malaysia industry is still required [17]. Most of the investigations related to HAVS diseases are merely different from each country due to different climatic environment condition and work activities [24] Thus, the occupational health surveillance in which 'early detection' and 'prevention' for determining the health cause-effect due to HTV in the workplace acquire attention to improve occupational health among workers $[4,25]$.

Furthermore, most of the established hand-transmitted assessments are not deeply revealing the health cause-effect due to complicated exposure dose response relationship during the data analysis process either by linear or neural network methods $[25,26,27,28]$. The evaluations of the health cause-effect are the important components for predicting the HTV exposure prevalence to HAVS, particularly for Malaysian research that seeks to construct a cause-effect relationship model between HTV risk measures and HAVS health consequences $[9,11,13]$. Su et al. (2014) stated that the presence of the symptoms associated to HAVS and the high level of daily vibration exposure in the tropical environment could contribute to the initial factor for controlling HTV hazard based on work activity. Hence, the analysis of cause-effect relationship between the HTV and the severity of HAVS assessment need to be reliably tested using prediction health cause-effect model [12,29].

Through research on HAVS among hand-held grass-cutting workers in Malaysia done by Universiti Tun Hussein Onn Malaysia (UTHM), the study found that there are symptoms that workers will experience disability in hand arm due to vibration exposure from grass cutter machine. The subject of this research focuses on the occupational health cause-effect when operating the high vibrating machine on site. The study also revealed that hand-held grass-cutting workers induce to high risk of suffering HAVS as chronic health [30].

Safety and health cause-effect do important procedure for employers and employees to understand how to mitigate the HTV hazard which can benefit grass-cutting operators. Research has been recognized on human response to hand arm vibration measures, but has not penetrated at using a neural network methods by means of artificial neural network to combine objective and subjective data in predicting health cause-effect among hand-held grass-cutting workers. Additionally, subjective surveys of HAVS have been proposed by scholars in Malaysia, yet no one has looked at classifying both hand numerical scoring and hand grip strength assessment at the same time, and combine results with objective measures to predict health cause-effect model.
This research will attempt to show that an artificial neural network (ANN) can be developed to predict health cause-effect using both objective and subjective measures for hand-held grass-cutting workers using vibrating machine. The solution will explain both hand numerical scoring and hand grip strength measurement, view at working and social history as well as the hand disability symptoms of the workers, report hand-transmitted vibration at both the right and left handles of grass cutter machine. To the author's knowledge, there was no such study to design the process of hand arm vibration exposure risk assessment combining the health surveillance using subjective and objective measures on hand-held grass-cutting workers in Malaysia. This proposed process called hand arm vibration exposure risk assessment (HAVERA) will acquire intention to develop the health cause-effect prediction model of HTV which is integrated between engineering and administration control measure among hand-held grass-cutting workers in Malaysia. Therefore, this study intended to fill the gap by predicting health cause-effect of hand arm vibration exposure subjectively and objectively by ANN program.

\section{Methodology}

The research methodology involves the evaluation and prediction model of the hand arm vibration exposure risk assessment (HAVERA) method among hand-held grass-cutting workers and has been divided into two stages, the evaluation of the HAVERA process using objective and subjective measures (Stage 1) and the prediction health cause-effect model of the HAVERA process using linear and neural network approaches (Stage 2). Fig. 1 shows the overview of the research methodology for the HAVERA method design process.

\subsection{Data Collection}

A week before data collection starts, section manager of PROPEL Berhad was briefed by the author regarding the research on hand arm vibration exposure among hand-held grass-cutting workers. An interview and informal conversation have been conducted with the top management of PROPEL Berhad about the grass-cutting operation process from the occupational safety and health point of view. Thus, the first step was taken by the author to assess the risk associated to hand-held grass-cutting workers at expressway. This information is required by the author to determine the risk likelihood and severity during maintaining grass at expressway area. This first step of data collection is called HIRARC assessment and analysis. The data collection started early in the morning during roll call activity. After that (Fig. 2a), at each section office, subcontractor of hand-held grass-cutting workers was called for explanation associated to HAVERA questionnaires. 

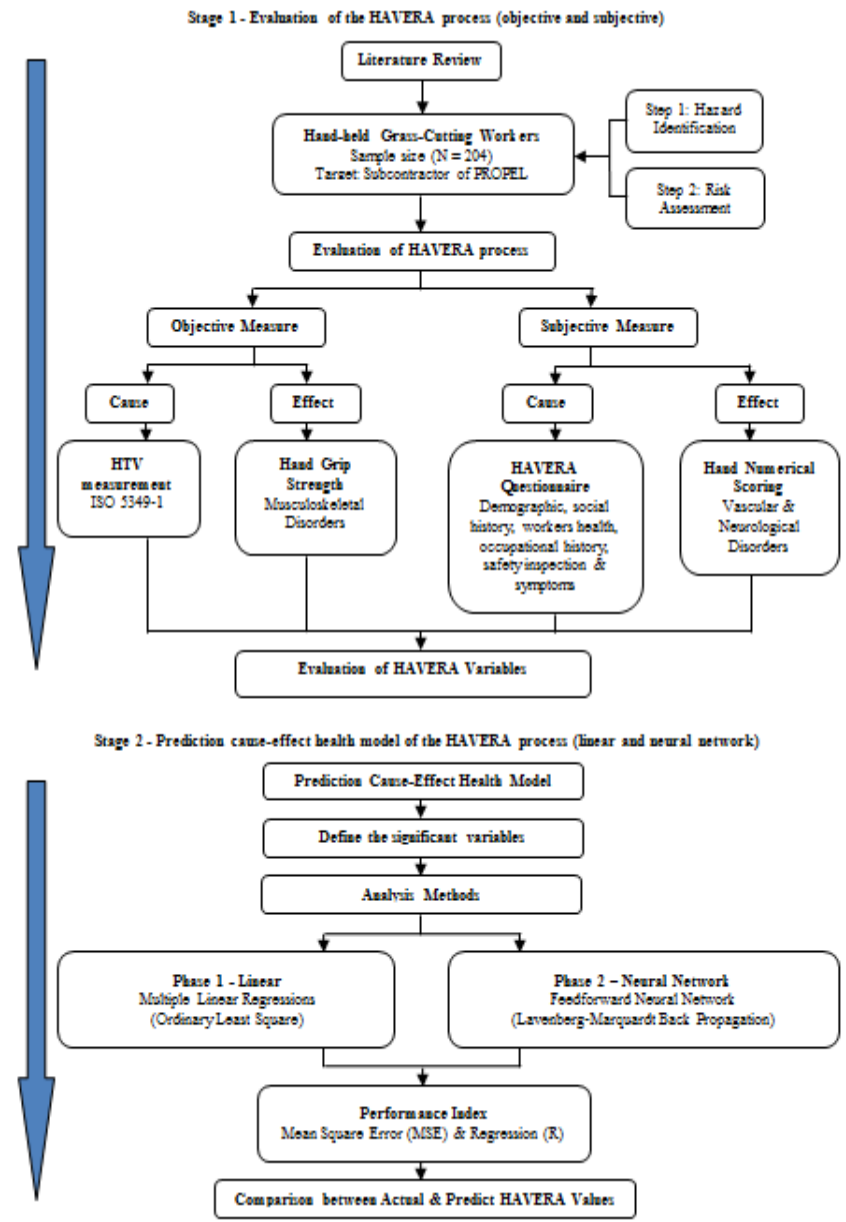

Fig. 1: Design process of HAVERA method

The interview and observation techniques were used to answer the HAVERA questionnaires. Knowledge on occupational safety and health is needed in determining the hand arm vibration symptoms due to grass-cutting operation. Hence, professional judgement by the author assisted by NIOSH staff is sufficient to observe the health effect especially in selecting the numerical scoring due to finger blanching or colour changing. It is the most suitable time to see any abnormalities on workers' hand in the morning since they have not been exposed to hand-transmitted vibration for at least 12 hours. The measurement of weight and height were done using weight scales (Fig. 2b) and height gauge (Fig. 2c), respectively. Before dismissing the assembly, each worker needed to pull out the dynamometer (Fig. 2d) at least 2 times measurement for the right and left hands, respectively. The hand grip strength measurement before work or exposed to hand-transmitted vibration was taken:-

i. The workers were briefed on the purpose of the human vibration meter and that it is not a game device.

ii. The workers were also informed that the human vibration meter will not interfere with their normal duties and they should continue to work as usual until the human vibration meter is removed.

iii. Instruction was also given to the workers not to remove the triaxial accelerometer unless absolutely necessary and not to cover the accelerometer with a glove.

Before attaching the tri-axial accelerometer to the handle, the accelerometer was calibrated following the sensitivity level of each axis to make sure the correct measurement was taken using calibrator (Fig. 3) (Brand: Kistler; Model: 8921; Serial No: C2053054).
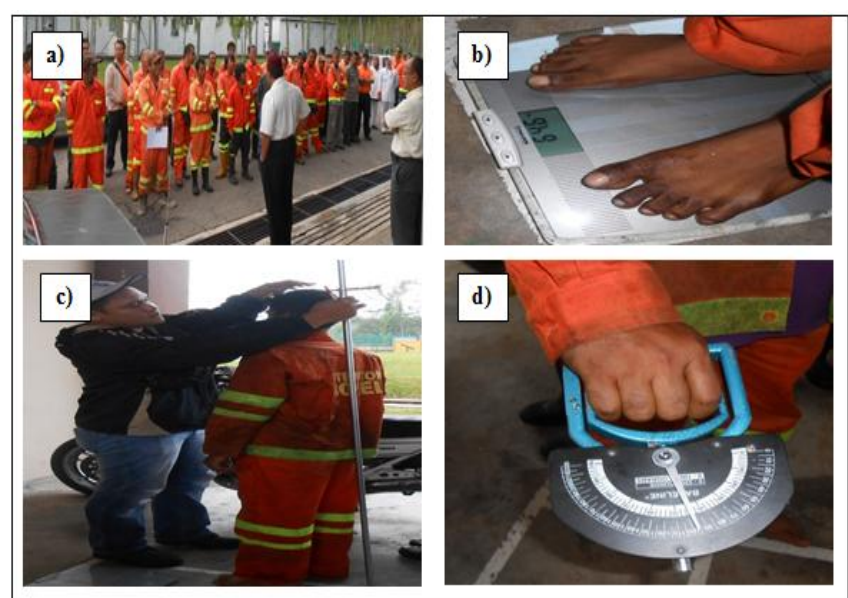

Fig. 2: a) Weekly roll call activity; b) weight scale; c) height gauge; d) hand grip strength measurement

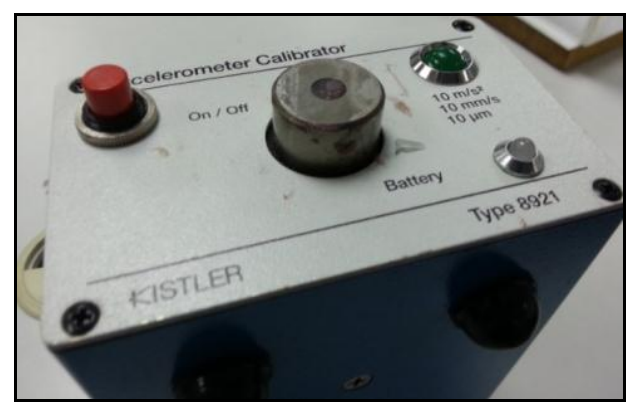

Fig. 3: The tri-axial accelerometer calibrator

Blaze software version 6.1.1 for Larson Davis Human Vibration Meter (Brand: Larson Davis; Model: HVM 100; Serial: 02336) was used to record the hand arm vibration exposure (Fig. 4). Raw, h-weighted tri-axial hand arm vibration measurement were collected by using integrated circuit piezoelectric (ICP) accelerometer (Brand: PCB Piezotronics; Model: SEN041F; Serial: P149376; Sensitivity: $10.59 \mathrm{mV} / \mathrm{g}$ (z-axis), $10.41 \mathrm{mV} / \mathrm{g}$ (y-axis), 10.43 $\mathrm{mV} / \mathrm{g}$ (x-axis)) mounted on both left and right handles of handheld grass-cutting machine, respectively, as shown in Fig. 5.

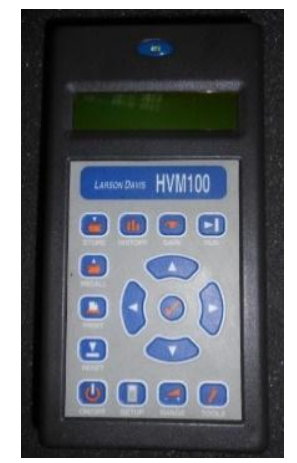

Fig. 4: Larson Davis human vibration meter. (HVM 100)

The tri-axial piezoelectric accelerometer handle mounted adapter was inserted between the worker's fingers and the handle. Hence, it was fixed on the handle by drafting tape. The right hand was used for controlling the speed cutting operation. Each handle was measured one time with sampling rate of 1 second period for 4 minutes. However, to produce the statistically significant vibration data, at least 60 seconds should be enough for hand-transmitted vibration exposure data collection. After finishing the handtransmitted vibration measurement, the subjects were asked to pull the dynamometer for after work hand grip strength force. 

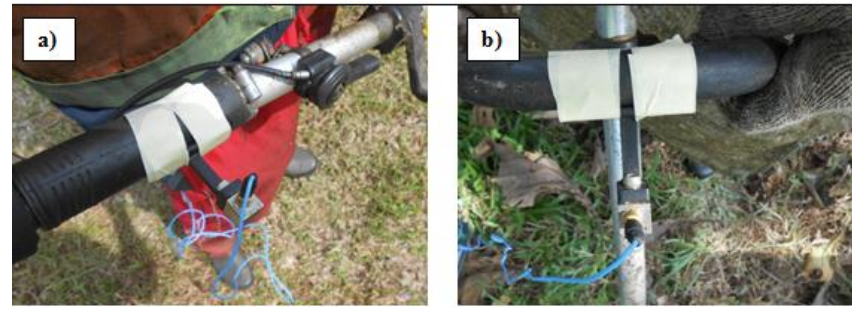

Fig. 5: The accelerometer attaches position, a) right handle, and b) left handle.

In general, there have been five instrumentations used to assist the data collection process which are human vibration meter, tri-axial accelerometer, dynamometer, HAVERA questionnaires and job hazard analysis form. Data collection process did not run continuously since it needed permission for data collection from the section manager as well as time constraint. The meaning of time constraint here is the author is not allowed to take measurement during weekends and public holidays since there is heavy traffic. Consequently, the author was allocated approximately 10 months for 204 onsite subjects' data collection. Furthermore, a total of eight expressway sections had been covered from MalaysiaSingapore second crossing expressway until Kuala Lumpur expressway operated by PLUS Berhad. In spite of that, normally, maximum 6 workers are assigned per day for hand-transmitted vibration exposure measurement due to far field location, limitation of man power as well as the research equipment. However, the cost expenses for monitoring hand arm vibration exposure among hand-held grass-cutting workers are considered low.

\subsection{Predicting Cause-effect Health Model}

There are several predictive modelling approaches proposed for the past few years. In general, a linear modelling technique such as multiple regressions is the most common method used by researcher. Another option is Artificial Neural Network (ANN) which is able to solve categorical data which is not yet applied extensively by human factor practitioners and ergonomics. However, there is still a research argument on the practitioner findings in the field of health cause-effect study by means of the type of prediction model selected due to the different answers published. There are many factors to be considered in the selection of prediction manner associated with data processing itself. This selection is driven by the research objectives and the specific case study data capabilities. In practice, the aims to develop prediction model is to maximize the accuracy of proposed model and its validity to be tested in the future.

There are a number of limitations or uncontrolled parameter such as the location, environment, and human capacity which made the model can only be tested in a certain sample areas. For example, the health effect of hand arm vibration in Malaysia population should be different from other countries, especially in the cases where the environment condition and the scope of work activities might produce different data set. Hence, it is a positive advice to investigate the selected input factors for predictive model by each work unit activity. In health risk assessment, each work unit will be exposed to harmful event associated to the likelihood and severity of incident to happen. The selections of causes that induce to HAVS are being chosen to develop predictive model, hence give benefit to management if the models are appropriately used to improve productivity and workers' health. The flowchart of prediction health cause-effect model derivation is shown in Figure 6.

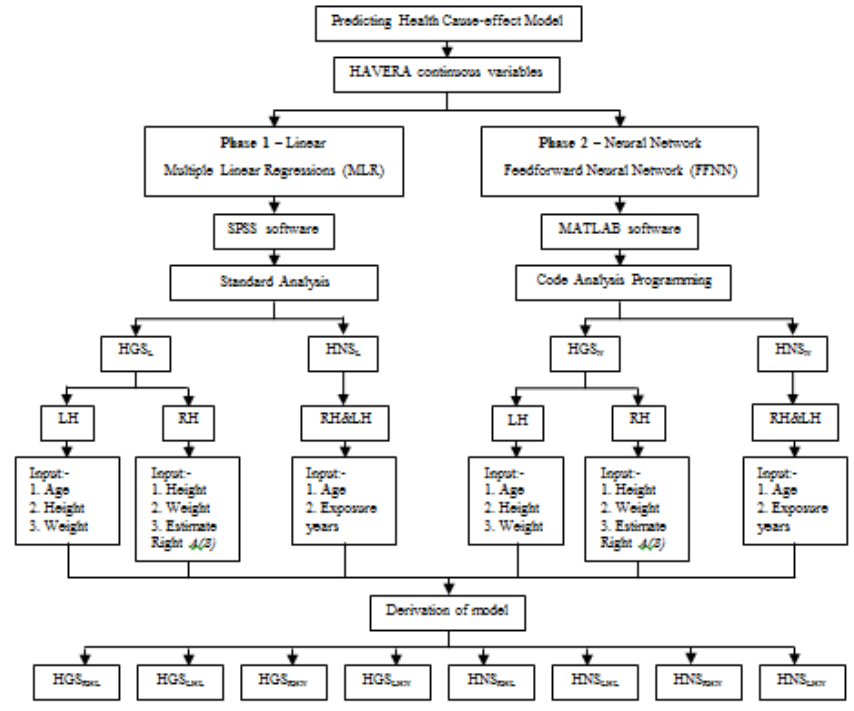

*Note:

(a) Linear Hand Grip Strength $\left(\mathrm{HGS}_{2}\right)$, Linear Hand Numerical Scoring $\left(\mathrm{HNS}_{2}\right)$, Neural Network Hand Grip Strength (HGS $)$ \& Neural Network Hand Numerical Scoring $\left(\mathrm{HNS}_{\mathrm{N}}\right)$.

(b) Right Hand (RH) \& Laft Hand (LH)

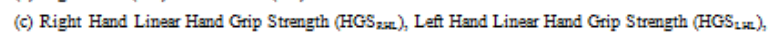

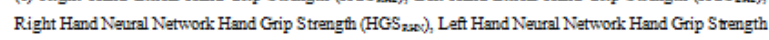
(HGS 2 wo), Right Hand Linear Hand Numerical Scoring $\left(\mathrm{HNS}_{3 \mathrm{nnn}}\right.$ ), Left Hand Linaar Hand Numerical Scoring $\left(\mathrm{HNS}_{1 \mathrm{n}}\right)$, Right Hand Neural Network Hand Numerical Scoring $\left(\mathrm{HNS}_{z \mathrm{n}}\right)$ \& Left Hand Neural Network Hand Numerical Scoring ( $\left(\mathrm{WNS}_{2 \mathrm{kN})}\right.$

Fig. 6: Flowchart of predicting health cause-effect model derivation among hand-held grass-cutting workers

\subsection{Performance Index}

After completing the derivation of HAVS prediction cause-effect model among hand-held grass-cutting workers, including linear and neural network analysis process, the performance index will appear in output screen as a model summary both for linear model and neural network model. The performance index of both models is able to produce Mean Square Error (MSE) and Regression (R) quantitative value after the analysis process was done. The MSE depicts average squared difference between predictions and input while $\mathrm{R}$ measures the correlation between predictions and input, respectively. Lower values of MSE are better while R value of 1 means a close relationship.

The MSE is compared between prediction and input value based on Equation 1 while R defines the relationship between the independent and dependent variables. In practice the value of MSE should be close to " 0 " to produce high significant for both linear and neural network HAVS prediction models. Normally, the small number of MSE is associated with the R value near to " 1 " which defines that the relationship between output and input data is strong.

$M S E=\frac{1}{n} \sum_{i=1}^{n}\left(o_{i}-t_{i}\right)^{2}$

where, $\mathrm{n}$ is the number of data, $\mathrm{o}$ is the predicted value and $\mathrm{t}$ is the target value after normalization.

Finally, the reliability of prediction model will be evaluated using relative error when compared to the predicted and actual data. To ensure correct model proposed, the predicted model result was tested using the actual data, for which the relative error was obtained using Equation 2. Hence, the HAVS prediction model developed here is expected to be suitable to determine the choric hand effect (HGS and HNS) due to vibration exposure of among hand-held grass-cutting workers based on the HAVERA significant variables. The prediction data will be compared with the actual data to depict performance index comparison value, hence identifying which is the best technique to simulate the data obtained in the future. 


$$
H G S / H N S=\frac{H G S / H N S_{\text {actual }}-H G S / H N S_{\text {predicted }}}{H G S / H N S_{\text {actual }}}
$$

\section{Methodology}

\subsection{Performance Index of Phase 1 and Phase 2}

The Phase 1 and Phase 2 performance index results of prediction continuous HAVERA cause-effect of both hands grip strength and numerical scoring health model among hand-held grass-cutting workers are divided into two sections: 1) Regression (R) Value and 2) Mean Square Error (MSE) Value.

\subsubsection{Regression (R) Value}

A comparison of regression $(\mathrm{R})$ value between linear and neura network prediction model is shown in Table 1. For the linear and neural network right hand grip strength (HGSRH), the $\mathrm{R}$ value is 0.99916 and 0.99980 while left hand grip strength (HGSLH), the $R$ value is 0.93987 and 0.99967 , respectively. In addition, the $R$ value of linear and neural network right hand numerical scoring (HNSRH) is 0.99924 and 0.99950 while left hand numerical scoring (HNSLH) is 0.99880 and 0.99971, respectively. The difference of $\mathrm{R}$ value between linear and neural network prediction model for all four models ranged from 0.0598 to 0.00026 .

Table 1: Linear and neural network regression (R) performance index of prediction model in percentage

\begin{tabular}{lcc}
\hline \multirow{2}{*}{ Prediction Model } & \multicolumn{2}{c}{ Regression, (R) \% } \\
\cline { 2 - 3 } & Linear & Neural Network \\
\hline Right Hand Grip Strength & 99.92 & 99.98 \\
Left Hand Grip Strength & 93.99 & 99.97 \\
Right Hand Numerical Scoring & 99.92 & 99.95 \\
Left Hand Numerical Scoring & 99.88 & 99.97 \\
\hline
\end{tabular}

The regression of HAVERA model for both hands grip strength and hands numerical scoring have found that the neural network prediction model regression $(\mathrm{R})$ values were close to 1 as compared to linear prediction R values. However, both linear and neural network model showed the $\mathrm{R}$ value was near to 1 . The highest regression value was neural network right hand grip strength (HGSRHN) with the R value 0.99980 and the lowest regression value was linear left hand grip strength (HGSLHL) with the $\mathrm{R}$ value 0.93987 . The differences of $R$ values between linear and neural network HAVERA prediction model was 0.00064 for right hand grip strength (HGSRH), 0.0598 for left hand grip strength (HGSLH), 0.00026 for right hand numerical scoring (HNSRH) and 0.00091 for left hand numerical scoring (HNSLH). These findings indicated the suitability of the proposed algorithm of HAVERA prediction model using FFNN as the health monitoring tools among hand-held grass-cutting workers. Indeed, there was no significant difference between the right hand grip strength and right hand numerical scoring $(\mathrm{p}=0.030)$ while there was a significant difference between the left hand grip strength and left hand numerical scoring $(\mathrm{p}=0.319)$.

\subsubsection{Mean Square Error (MSE) Value}

A comparison of mean square error (MSE) value between linear and neural network prediction model is shown in Table 2. For the linear and neural network right hand grip strength (HGSRH), the MSE value is 0.00282 and 0.000061 while for left hand grip strength (HGSLH), the MSE value is 0.00287 and 0.000044 , respectively. In addition, the MSE value of linear and neural network right hand numerical scoring (HNSRH) is 0.00279 and 0.000002 while left hand numerical scoring (HNSLH) is 0.00260 and 0.000081 , respectively. The difference of MSE value between linear and neural network prediction model for all four models ranged from 0.002519 to 0.002826 .
Table 2: Comparison between linear and neural network mean square error (MSE) performance index in percentage

\begin{tabular}{lcc}
\hline \multirow{2}{*}{ Prediction Model } & \multicolumn{2}{c}{ Mean Square Error, (MSE) \% } \\
\cline { 2 - 3 } & Linear & Neural Network \\
\hline Right Hand Grip Strength & 0.282 & 0.0061 \\
Left Hand Grip Strength & 0.287 & 0.0044 \\
Right Hand Numerical Scoring & 0.279 & 0.0002 \\
Left Hand Numerical Scoring & 0.260 & 0.0081 \\
\hline
\end{tabular}

The mean square error of HAVERA model for both hands grip strength and hands numerical scoring showed that the neural network prediction model mean square error (MSE) values were close to 0 as compared to linear prediction MSE values. However, both linear and neural network model showed the MSE values near to 0 . The smallest mean square error value was neural network right hand numerical scoring (HNSRHN) with the MSE value 0.000002 and the biggest mean square error value was linear left hand grip strength (HGSLHL) with the MSE value 0.00287. The differences of MSE value between linear and neural network HAVERA prediction model was 0.00276 for right hand grip strength (HGSRH), 0.00283 for left hand grip strength (HGSLH), 0.00279 for right hand numerical scoring (HNSRH) and 0.00252 for left hand numerical scoring (HNSLH). This finding indicated that the best fit of the proposed algorithm HAVERA prediction model using FFNN as the predicted value is close to the measured value during on site observation among hand-held grass-cutting workers. Indeed, the small value of MSE depicted a close relationship between a significant HAVERA cause and effect variables induced to loss of hand grip strength and finger blanching.

\subsection{Reliability of HAVERA Prediction Model}

The results of reliability testing of linear and neural network HAVERA cause-effect health model among hand-held grasscutting workers have been divided into two sections: 1) Hand Grip Strength Test and 2) Hand Numerical Scoring Test. The test consists of right and left hand prediction model based on hand grip strength and hand numerical scoring assessment.

\subsubsection{Hand Grip Strength Test}

The results for reliability testing of the continuous HAVERA prediction model based on hand grip strength are shown in Table 3 . All test samples have small value of relative error. The difference of relative error value for linear and neural network right hand test prediction model ranged between negative 0.356 and positive 0.109 . Meanwhile, the difference of relative error value for linear and neural network left hand test prediction model ranged between negative 0.266 and positive 0.205 .

Table 3: Comparison of the linear and neural network hand grip strength result for actual and predicted data. (8 samples)

\begin{tabular}{|c|c|c|c|c|c|c|c|c|c|c|}
\hline \multirow{2}{*}{$\begin{array}{c}\mathbf{S} \\
\dot{\mathbf{N}}\end{array}$} & \multicolumn{3}{|c|}{ Right Hand } & \multicolumn{2}{|c|}{ Rel. Error } & \multicolumn{3}{|c|}{ Left Hand } & \multicolumn{2}{|c|}{ Rel. Error } \\
\hline & A & $\begin{array}{l}\text { L. } \\
\text { P. }\end{array}$ & $\begin{array}{l}\text { N. } \\
\text { P. }\end{array}$ & $\mathbf{L}$ & $\mathbf{N}$ & $\mathbf{A}$ & $\begin{array}{l}\text { L. } \\
\text { P. }\end{array}$ & $\begin{array}{l}\text { N. } \\
\text { P. }\end{array}$ & $\mathbf{L}$ & $\mathbf{N}$ \\
\hline 1 & $\begin{array}{l}1 \\
6\end{array}$ & $\begin{array}{c}22.3 \\
2\end{array}$ & $\begin{array}{c}16.6 \\
2\end{array}$ & $\begin{array}{c}0.39 \\
5\end{array}$ & $\begin{array}{c}0.03 \\
9\end{array}$ & & $\begin{array}{c}39.0 \\
6\end{array}$ & $\begin{array}{c}41.1 \\
0\end{array}$ & $\begin{array}{c}0.04 \\
7\end{array}$ & $\begin{array}{c}0.00 \\
2\end{array}$ \\
\hline 2 & $\begin{array}{l}2 \\
3\end{array}$ & $\begin{array}{c}25.5 \\
4\end{array}$ & $\begin{array}{c}23.3 \\
4\end{array}$ & $\begin{array}{c}0.11 \\
0\end{array}$ & $\begin{array}{c}0.01 \\
5\end{array}$ & 3 & $\begin{array}{c}38.4 \\
0\end{array}$ & $\begin{array}{c}30.4 \\
3\end{array}$ & $\begin{array}{c}0.28 \\
0\end{array}$ & $\begin{array}{c}0.01 \\
4\end{array}$ \\
\hline 3 & $\begin{array}{l}2 \\
7\end{array}$ & $\begin{array}{c}27.3 \\
8\end{array}$ & $\begin{array}{c}27.1 \\
8\end{array}$ & $\begin{array}{c}- \\
0.01 \\
4\end{array}$ & $\begin{array}{c}- \\
0.00 \\
7\end{array}$ & 3 & $\begin{array}{c}38.7 \\
6\end{array}$ & $\begin{array}{c}36.2 \\
5\end{array}$ & $\begin{array}{c}- \\
0.07 \\
7\end{array}$ & $\begin{array}{c}- \\
0.00 \\
7\end{array}$ \\
\hline 4 & $\begin{array}{l}2 \\
8\end{array}$ & $\begin{array}{c}27.8 \\
4\end{array}$ & $\begin{array}{c}28.1 \\
4\end{array}$ & $\begin{array}{c}0.00 \\
6\end{array}$ & $\begin{array}{c}0.00 \\
5\end{array}$ & 3 & $\begin{array}{c}38.4 \\
0\end{array}$ & $\begin{array}{c}30.4 \\
3\end{array}$ & $\begin{array}{c}0.28 \\
0\end{array}$ & $\begin{array}{c}0.01 \\
4\end{array}$ \\
\hline 5 & $\begin{array}{l}2 \\
6\end{array}$ & $\begin{array}{c}26.9 \\
2\end{array}$ & $\begin{array}{c}26.2 \\
2\end{array}$ & $\begin{array}{c}- \\
0.03 \\
5\end{array}$ & $\begin{array}{c}- \\
0.00 \\
8\end{array}$ & 7 & $\begin{array}{c}38.8 \\
2\end{array}$ & $\begin{array}{c}37.2 \\
2\end{array}$ & $\begin{array}{c}- \\
0.04 \\
9\end{array}$ & $\begin{array}{c}- \\
0.00 \\
6\end{array}$ \\
\hline 6 & $\begin{array}{l}2 \\
0\end{array}$ & $\begin{array}{c}24.1 \\
6\end{array}$ & $\begin{array}{c}20.4 \\
6\end{array}$ & $\begin{array}{c}- \\
0.20 \\
8\end{array}$ & $\begin{array}{c}- \\
0.02 \\
3\end{array}$ & 0 & $\begin{array}{c}38.4 \\
0\end{array}$ & $\begin{array}{c}30.4 \\
3\end{array}$ & $\begin{array}{c}- \\
0.28 \\
0\end{array}$ & $\begin{array}{c}- \\
0.01 \\
4\end{array}$ \\
\hline 7 & $\begin{array}{l}3 \\
3\end{array}$ & $\begin{array}{c}30.1 \\
4\end{array}$ & $\begin{array}{c}32.9 \\
4\end{array}$ & $\begin{array}{c}0.08 \\
7\end{array}$ & $\begin{array}{c}0.00 \\
2\end{array}$ & $\begin{array}{l}4 \\
0\end{array}$ & $\begin{array}{c}39.0 \\
0\end{array}$ & $\begin{array}{c}40.1 \\
3\end{array}$ & $\begin{array}{c}0.02 \\
5\end{array}$ & 0.00 \\
\hline
\end{tabular}




$\begin{array}{ccccccccccc}8 & 3 & 31.0 & 34.8 & 0.11 & 0.00 & 5 & 39.6 & 49.8 & 0.20 & 0.00 \\ & 5 & 6 & 6 & 3 & 4 & 0 & 0 & 3 & 8 & 3\end{array}$

* Note: S. N. - Sample No.; L. P. - Linear Predicted; N. P. - Neural Network Predicted; A - Actual; Rel. Error - Relative Error; L - Linear; N Neural Network

The result of right hand grip strength prediction model showed a reliable association between height, weight and estimated right hand daily vibration exposure with right hand grip strength measurement (HAVERA process) in accordance to the mean of 8 samples with relative error value of -0.011 for neural network technique while -0.070 for linear technique. Meanwhile, the result of left hand grip strength prediction model showed a reliable association between height, weight and age with left hand grip strength measurement (HAVERA process) in accordance with the mean of 8 samples with relative error value of -0.007 for neural network technique and -0.086 for linear technique. This result indicated that the reliability of neural network prediction model technique is higher compared to linear technique. The biggest relative error value for neural network right hand grip strength (HGSRHN) was -0.039 where the means of actual measurement is 16 and the predicted value is 16.62 . The smallest relative error value for HGSRHN was 0.002 where the means of actual measurement is 33 and the predicted value is 32.94 . Besides that, the biggest relative error value for neural network left hand grip strength (HGSLHN) was 0.014 where the means of actual measurement is $30 \mathrm{~kg}$ and the predicted force is $30.43 \mathrm{~kg}$. The smallest relative error value for HGSLHN was -0.002 where the means of actual measurement is $41 \mathrm{~kg}$ and the predicted force is $41.10 \mathrm{~kg}$. Thus, the study revealed that the both hands grip strength neural network health prediction model can be an indicator for the hand-held grass-cutting workers management in performing health surveillance.

\subsubsection{Hand Numerical Scoring Test}

The results for reliability test of the continuous HAVERA prediction model based on hand numerical scoring are shown in Table 4. All test samples have small value of relative error. The difference of relative error value for linear and neural network right hand test prediction model ranged between negative 0.686 and positive 0.256. Meanwhile, the difference of relative error value for linear and neural network left hand test prediction model ranged between negative 0.859 and positive 0.243 .

Table 4: Comparison of the linear and neural network hand numerical scoring result for actual and predicted data. (8 samples)

\begin{tabular}{|c|c|c|c|c|c|c|c|c|c|c|}
\hline \multirow{2}{*}{$\begin{array}{l}\mathbf{S} \\
\dot{N}\end{array}$} & \multicolumn{3}{|c|}{ Right Hand } & \multicolumn{2}{|c|}{ Rel. Error } & \multicolumn{3}{|c|}{ Left Hand } & \multicolumn{2}{|c|}{ Rel. Error } \\
\hline & A & $\begin{array}{l}\text { L. } \\
\text { P. }\end{array}$ & $\begin{array}{l}\text { N. } \\
\text { P }\end{array}$ & $\mathbf{L}$ & $\mathbf{N}$ & $\mathbf{A}$ & & N. & $\mathbf{L}$ & $\mathbf{N}$ \\
\hline 1 & 6 & $\begin{array}{c}6.3 \\
5\end{array}$ & 6.00 & $\begin{array}{c}0.05 \\
8\end{array}$ & 0 & 9 & $\begin{array}{c}7.8 \\
9\end{array}$ & 8.97 & 4 & $\begin{array}{c}0.00 \\
3\end{array}$ \\
\hline 2 & 9 & $\begin{array}{c}7.6 \\
4\end{array}$ & 9.00 & $\begin{array}{c}0.15 \\
1\end{array}$ & $\begin{array}{c}0.00 \\
0\end{array}$ & 9 & $\begin{array}{c}7.8 \\
9\end{array}$ & 8.97 & $\begin{array}{c}0.12 \\
4\end{array}$ & $\begin{array}{c}0.00 \\
3\end{array}$ \\
\hline 3 & 5 & $\begin{array}{c}5.9 \\
2\end{array}$ & 5.00 & $\begin{array}{c}- \\
0.18 \\
4\end{array}$ & $\begin{array}{c}0.00 \\
0\end{array}$ & 9 & $\begin{array}{c}7.8 \\
9\end{array}$ & 8.97 & $\begin{array}{c}0.12 \\
4\end{array}$ & $\begin{array}{c}0.00 \\
3\end{array}$ \\
\hline 4 & $\begin{array}{l}1 \\
2\end{array}$ & $\begin{array}{c}8.9 \\
3\end{array}$ & $\begin{array}{c}12.0 \\
0\end{array}$ & $\begin{array}{c}0.25 \\
6\end{array}$ & & & $\begin{array}{c}9.0 \\
0\end{array}$ & & & $\begin{array}{c}0.00 \\
7\end{array}$ \\
\hline 5 & $\begin{array}{l}1 \\
1\end{array}$ & $\begin{array}{c}8.5 \\
0\end{array}$ & $\begin{array}{c}11.0 \\
0\end{array}$ & $\begin{array}{c}0.22 \\
7\end{array}$ & $\begin{array}{c}0.00 \\
0\end{array}$ & 3 & $\begin{array}{c}5.6 \\
7\end{array}$ & 3.09 & $\begin{array}{c}0.88 \\
9\end{array}$ & $\begin{array}{c}0.03 \\
0\end{array}$ \\
\hline 6 & 5 & $\begin{array}{c}5.9 \\
2\end{array}$ & 5.00 & $\begin{array}{c}0.18 \\
4\end{array}$ & $\begin{array}{c}0.00 \\
0\end{array}$ & 3 & $\begin{array}{c}5.6 \\
7\end{array}$ & 3.09 & $\begin{array}{c}0.88 \\
9\end{array}$ & $\begin{array}{c}0.03 \\
0\end{array}$ \\
\hline 7 & 3 & $\begin{array}{c}5.0 \\
6\end{array}$ & 3.00 & $\begin{array}{c}- \\
0.68 \\
6\end{array}$ & $\begin{array}{c}0.00 \\
0\end{array}$ & 3 & $\begin{array}{c}5.6 \\
7\end{array}$ & 3.09 & $\begin{array}{c}- \\
0.88 \\
9\end{array}$ & $\begin{array}{c}- \\
0.03 \\
0\end{array}$ \\
\hline 8 & 7 & $\begin{array}{c}6.7 \\
8 \\
\end{array}$ & 7.00 & $\begin{array}{c}0.03 \\
2 \\
\end{array}$ & $\begin{array}{c}0.00 \\
0 \\
\end{array}$ & 9 & $\begin{array}{c}7.8 \\
9 \\
\end{array}$ & 8.97 & $\begin{array}{c}0.12 \\
4\end{array}$ & $\begin{array}{c}0.00 \\
3 \\
\end{array}$ \\
\hline
\end{tabular}

* Note: S. N. - Sample No.; L. P. - Linear Predicted; N. P. - Neural Network Predicted; A - Actual; Rel. Error - Relative Error; L - Linear; N Neural Network.
The result of right hand numerical scoring prediction model showed a reliable association between age and working experience with right hand numerical scoring measurement (HAVERA process) in accordance to the mean of 8 samples of relative error value 0.000 for neural network technique while -0.056 for linear technique. Meanwhile, the result of left hand numerical scoring prediction model showed a reliable association between age and working experience with left hand numerical scoring measurement (HAVERA process) in accordance to the mean of 8 samples of relative error value -0.009 for neural network technique and 0.240 for linear technique. This result also indicated that the reliability of neural network prediction model technique is higher compared to linear technique. The biggest and smallest relative error value for neural network right hand numerical scoring (HNSRHN) was 0.000 where the actual score is 6 and the predicted score is 6.00 . Besides that, the biggest relative error value for neural network left hand numerical scoring (HNSLHN) was 0.030 where the actual score is 3 and the predicted score is 3.09 . The smallest relative error value for HNSLHN was 0.003 where the actual score is 9 and the predicted score is 8.97. Thus, the study revealed that the both hands numerical scoring neural network health prediction model can be an indicator for the hand-held grass-cutting workers management in performing health surveillance.

\section{Conclusion}

Over the past two years of this research program, the hand arm vibration exposure risk assessment (HAVERA) cause-effect process has been introduced to assess the hand arm vibration exposure to risks of hand arm vibration syndrome (HAVS) among hand-held grass-cutting workers. The HAVERA prediction model has been developed through the process of measuring and determining variables at two different stages which are evaluation of the HAVERA process and prediction health effect model of the HAVERA process (linear and neural network). This has led to a model predicted by and for occupational safety and health practitioners, with expert facilities and monitoring.

The main objective of this research was to develop prediction health cause-effect model of HAVERA process among hand-held grass-cutting workers using linear and neural network approaches. An algorithm was created using feed forward neural network consists of right hand grip strength, left hand grip strength, right hand numerical scoring and left hand numerical scoring. All of neural network prediction model have regression coefficient value between 0.96 to 1 meanwhile linear prediction models have regression coefficient value between 0.06 to 0.46 . Therefore, the performance indexes of neural network prediction model indicate regression value closed to 1 and means square error value closed to 0 as compared to linear prediction model. This study also conclude that the high reliability in using feed forward neural network for determine hand arm vibration exposure prediction model.

Based on the results obtained so far, it can be concluded that the HAVERA process is suitable for use when assessing the workers' health change in hand arm vibration exposure risk before, during and after a health surveillance implementation, as well as for the management to ensure the practicality of the administrative and engineering control measures for hand-transmitted vibration mitigation. The prediction cause-effect health model was also found to be practically reliable and applicable to hand-held grass-cutting workers. By proposing HAVERA hand grip strength and hand numerical scoring cause-effect health prediction model, the management and workers are able to monitor the health condition due to hand arm vibration hazard.

\section{Acknowledgement}

This research is fully supported by NIOSH grant, 03.05/03/NG04_GRASSCUTTER/2014. The authors fully acknowledged Universiti Tun Hussein Onn Malaysia (UTHM) 
and PROPEL Berhad for the university and industry linkage which makes this important research viable and effective.

\section{References}

[1] Bovenzi, M. (1998). Exposure-response relationship in the handarm vibration syndrome: an overview of current epidemiology research. Int Arch Occup Environ Health, 71, pp. 509-519

[2] Griffin, M. J. (1997). Measurement, evaluation, and assessment of occupational exposure to hand-transmitted vibration. Occupational and Environmental Medicine, 54, pp. 73-89.

[3] Edwards, D. J. \& Holt, G. D. (2005). Exposure to hand-arm vibration: implications of new statutory requirements. Building Research \& Information, 33(3), pp. 257-266.

[4] Cederlund, R., Iwarsson, S. \& Lundborg, G. (2007). Quality of life in Swedish workers exposed to hand-arm vibration. Occupational Therapy International, 14(3), pp. 156-169.

[5] Friden, J. (2001). Vibration damage to the hand: Clinical presentation, prognosis and length and severity of vibration required. Journal of Hand Surgery, 26B(5), pp. 471-474.

[6] Mansfield, N. J. (2005). Human Response to Vibration. United Kingdom: CRC Press LLC.

[7] Edwards, D. J. \& Holt, G. D. (2006). Hand-arm vibration exposure from construction tools: results of a field study. Construction Management and Economics, 24, pp. 209-217.

[8] Chan, K. F., Tan, C. W. C., Yeo, D. S. C., Tan, H. S. K. Tan, F. L Tan E. W., Szeto, G. P. Y. \& Cheng, A. S. K. (2011). Occupational Rehabilitation in Singapore and Malaysia. Journal Occupational Rehabilitation, 21, pp. 69-76.

[9] Widia, M. \& Dawal, S. Z. M. (2011). The effect of hand-held vibrating tools on muscle activity and grip strength. Australian Journal of Basic and Applied Sciences, 5(11), pp. 198-211.

[10] Su, T. A., Hoe, V. C. W., Masilamani, R. \& Awang Mahmud, A. B (2011). Hand-arm vibration syndrome among a group of construction workers in Malaysia. Occup. Environ. Med., 68(1), pp. 58-63.

[11] Tamrin, S. B. M., Jamalohdin, M. N., Ng, Y. G., Maeda, S. \& Ali, N. A. M. (2012). The characteristics of vibrotactile perception threshold among shipyard workers in a tropical environment. Industrial Health, 50, pp. 156-163.

[12] Kamat, S. R., Norhidayah, H., Halim, I. \& Hui, H. C. (2014). Effect of working posture and hand grip for carpal tunnel syndrome among aerospace workers. International Journal of Mechanical \& Mechatronics Engineering, 14(1), pp. 1-6.

[13] Su, A. T., Maeda, S., Fukumoto, J., Miyai, N. Isahak, M., Yoshioka, A., Nakajima, R., Bulgiba, A. \& Miyashita, K. (2014). A cross sectional study on hand-arm vibration syndrome among a group of tree fellers in a tropical environment. Industrial Health, 52, pp. 367-376.

[14] Department of Occupational Safety \& Health (2013). Statistik Kemalangan Pekerjaan Mengikut Sektor Sehingga March 2015. Malaysia: DOSH.

[15] Social Security Organization (2012). Annual Report. Malaysia: SOCSO.

[16] Virokannas, H., Anttonen, H. \& Niskanen, J. (1994). Health risk assessment of noise, hand-arm vibration and cold in railway track maintenance. International Journal of Industrial Ergonomics 13, pp. 247-22.

[17] Seri Rahayu, K., Nurulhuda, A. \& Rohana, A. (2013). Vibration of power hand tool and discomfort experience among malaysian industrial workers. Proc. of 2 th International Conference on Ergonomics, Universiti Malaya.

[18] Su, A. T., Maeda, S., Fukumoto, J., Darus, A., Hoe, V. C. W. Miyai, A., Isahak, M., Takemura, S., Bulgiba, A., Yoshimasu, K. \& Miyashita, K. (2013). Dose-response relationship between handtransmitted vibration and hand-arm vibration syndrome in a tropical environment. J Occup Environ Med, pp. 1-7.

[19] Lindsell, C. J. \& Griffin, M. J. (2002). Normative data for vascular and neurological tests of the hand-arm vibration syndrome. Int Arch Occup Environ Health, 75, pp. 43-54.

[20] Bovenzi, M. (2005). Health effect of mechanical vibration. G Ital Med Lav Erg, 27(1), pp. 58-64.

[21] Su, T. A. \& Hoe, V. C. W. (2008). Reliability of a Malay-translated questionnaire for use in a hand-arm vibration syndrome study in Malaysia. Singapore Medical Journal, 49(12), pp. 1038-1045.

[22] International Organization of Standards (2001). Mechanical vibration - Measurement and evaluation of human exposure to handtransmitted vibration - Part 1: General requirement. London: ISO 5349-1.
[23] Griffin, M. J. (2004). Minimum health and safety requirements for workers exposed to hand-transmitted vibration and whole-body vibration in the European Union; a review. Occupational Environment Medicine, 61, pp. 387-397.

[24] Su, A. T., Darus, A. Bulgiba, A., Maeda, S. \& Miyashita, K. (2012) The clinical features of hand-arm vibration syndrome in a warm environment $-\mathrm{A}$ review of the literature. Journal of Occupational Health, 54, pp. 349-360.

[25] Palmer, K. T., D’Angelo, S., Syddall, H., Griffin, M. J., Cooper, C. \& Coggon, D. (2014). Dupuytren's contracture and occupational exposure to hand-transmitted vibration. Journal of Occupational Environment Medicine, pp. 1-5.

[26] Kuijt-Evers, L. F. M., Bosch, T., Huysmans, M. A., de Looze, M. P. \& Vink, P. (2007). Association between objective and subjective measurements of comfort and discomfort in hand tools. Applied Ergonomics, 38, pp. 643-654.

[27] Shirokov, V., Krivtsova, I.,Bakhtereva, H., Shirokova, O. \& Granovskya, M. (2011). Qualitative and quantitative characteristics of pain syndrome in hand-arm vibration syndrome. Canadian Acoustics, 39(2), pp. 24-25.

[28] Edlund, M., Burstrom, L., Gerhardsson, L., Lundstrom, R., Nilsson, T., Sanden, H. \& Hagberg, M. (2014). A prospective cohort study investigating an exposure-response relationship among vibrationexposed male workers with numbness of the hands. Scand J Work Environ Health, 40(2), pp. 203-209.

[29] Bovenzi, M., Pinto, I., Picciolo, F., Mauro, M. \& Ronchese, F. (2011). Frequency weightings of hand-transmitted vibration for predicting vibration induced white finger. Scand J Work Environ Health, 37(3), pp. 244-252.

[30] Azmir, N. A., Ghazali, M. I. \& Yahya, M. N. (2014). Hand arm vibration and personal noise exposure characteristics of hand held grass cutter machine. The 21st International Congress on Sound and Vibration, Beijing. 